\title{
Human Papilloma Virus Related Oral Squamous Cell Carcinoma in Israel Population: Trends and Incidence
}

\author{
Yoav Leiser ${ }^{1 *}$, Yasmine Ghantous ${ }^{2 *}$, Sharon Akrish ${ }^{3}$ and Imad Abu El-naaj ${ }^{2}$ \\ ${ }^{1}$ Department of Maxillo-Facial Surgery, Rambam Medical Campus, Technion, Haifa, Israel \\ ${ }^{2}$ Department of Oral and Maxillofacial Surgery, Baruch Padeh Medical Center, Bar Ilan University, Galilee, Israel \\ ${ }^{3}$ Department of Pathology, Rambam Medical Campus, Technion, Haifa, Israel
}

*Corresponding authors: Yasmine Ghantous, Faculty of Medicine, Department of Oral and Maxillofacial Surgery, Baruch Padeh Medical Center, Bar Ilan University, Galilee, Israel, Tel: 972-522404014; E-mail: yasmen.ghantous@gmail.com

Yoav Leiser, Faculty of Medicine, Department of Maxillo-Facial Surgery, Rambam Medical Campus, Technion, Haifa, Israel, Tel: 047771438; Email:y_leiser@rambam.health.gov.il

The first and the second author contributed equally.

Received date: Jul 30, 2016; Accepted date: Aug 01, 2016; Published date: Aug 08, 2016

Copyright: (c) 2016 Leiser $Y$, et al. This is an open-access article distributed under the terms of the Creative Commons Attribution License, which permits unrestricted use, distribution, and reproduction in any medium, provided the original author and source are credited.

Citation: Leiser Y, Ghantous Y, Akrish S, et al. Human Papilloma Virus Related Oral Squamous Cell Carcinoma in Israel Population: Trends and Incidence. Arch Med. 2016, 8:4

\section{Abstract}

Aim: Our aim was to investigate the incidence of HPV related oral squamous cell carcinoma in the Israeli population.

Materials and methods: HPV typing was done by immunostaining for P16 of Tissue-Array sections, and PCR amplification from paraffin-embedded tissues [PCR Taq Mix (Promega Corporation, Israel)], on oral squamous cell carcinoma tissues spanning the period from 1996 to 2014.

Results: Immunoreactivity for P16 protein was found in 32 cases (39\%), HPV16 DNA typing was found in 23 cases $(28 \%)$, the HPV positive patients were significantly younger than HPV negative group, and demonstrated a higher histological differentiation.

Conclusion: A positive correlation between HPV infection and OSCC was found in the presented study; these results imply a possible involvement of HPV infection in oral carcinogenesis.

Keywords: Human papilloma virus; Carcinogenesis; Tissue array; Incidence; Oral squamous cell carcinoma; Survival; Prognosis

\section{Introduction}

Oral cavity cancer is among the most prevalent cancers, it is ranked third in developing countries (south central Asia) and eighth in developed countries [1].

Over $90 \%$ of oral cancers are categorized as squamous cell carcinoma (SCC) $[2,3]$. Despite the progress in treatment and diagnosis, the overall survival rate is only $40-50 \%$ [4], this is mainly due to the fact that head and neck carcinomas and specifically oral carcinomas tend to be diagnosed at a later stage due to public awareness, and also since there is no pain or disability until late stages.

The most important risk factor of head and neck carcinogenesis worldwide is smoking, with alcohol coming second. The risk is dose-dependent and the simultaneous use of both increases the risk many-fold, explaining some $75-85 \%$ of the cases. However, increasing trends in the incidence at specific sites suggest that other etiological factors are involved, and infection by certain high-risk types of human papillomavirus (i.e. HPV16) have been reported to be associated with head and neck cancers, in particular with oropharyngeal cancer. Still, associations with oral cancer are neither strong nor consistent when compared to molecularepidemiological data on HPV and oropharyngeal cancer.

The significance of HPV infection and its relationship to patient prognosis remains an important matter of debate, especially when considering the contradictory results presented in different published studies [5-8]; the majority of authors report a favorable prognosis in patients with HPVpositive OSCC [9-12]. However, other studies have suggested that the HPV group is at greater risk of recurrence or development of a second primary tumor [6]. Moreover, some authors did not find a significant correlation between HPV positivity and clinical outcome [13].

The objective of the present study is to investigate the prevalence of HPV related OSCC in the Israeli population, and its epidemiologic distribution in relation to all the Israeli subpopulation (Jews, Arabs and Druze). 


\section{Material and Methods}

\section{Patients}

The study cohort included 82 patients, whom are histopathology diagnosed with OSCC, spanning the period between 1996 and 2014. The medical files, including all the clinical and pathological data, were reviewed and data was collected regarding age, gender, primary anatomic localization, smoking and alcohol intake history, nodal status, tumor recurrences, histological classification, and overall survival (OS) of the patients.

All of the patients were diagnosed and treated at the Department of Oral and Maxillofacial Surgery, Rambam Health Care Campus, Haifa, Israel, and the Department of Oral and Maxillofacial Surgery, Padeh Poriya Medical Center. Inclusion criteria were oral cancer patients who were treated surgically with adequate clinico-pathological data, availability of sufficient paraffin-embedded tumor material presence, and histological proven oral cancer of squamous origin (verrucous carcinomas were categorized as well differentiated squamous cell carcinomas in this study). Exclusion criteria were malignancy other than oral cavity cancer (including buccal mucosa ICD9-145, tongue ICD9-141, floor of the mouth ICD9-144, lower alveolus ICD9-145, upper alveolus ICD9-145, and gum ICD9-43), second primary cancer, previous radiotherapy/chemotherapy to the oro-cervical region.

The study protocol was carried out with the approval of the local Human Research Ethics Committee. Following the initial biopsy or surgical resection, the tumor tissues were fixed in $4 \%$ neutral-buffered formalin, embedded in paraffin blocks, and archived according to institution protocol. In this study, the selected paraffin-embedded specimens were retrieved and processed to 5-micron thick sections, stained with hematoxylin-eosin, and reviewed by an experienced pathologist to confirm the diagnosis and the histologic classification grade.

For statistical analysis purposes, the tobacco and alcohol consumption of the patients were documented, and they were classified as "never consumers" or "current consumers". Former consumers who had quit tobacco and/or alcohol consumption more than two years before diagnosis were included in the "never consumers" group. Tobacco consumers were those individuals who consumed a cigarette or more daily. Mild alcohol drinking was defined as the consumption of 1-2 drinks per day, while heavy drinking was defined as the consumption of more than 2 drinks per day.

\section{Immunohistochemistry}

All archival tissue were analyzed for the presence of P16 presence. Tissue MicroArrays ${ }^{\circledR}$ was used in order to enable a fast, accurate and standardized method for screening cancer biopsies. Staining of the formalin fixed, paraffin-embedded 5 micron Tissue Array section was performed. First, slides were deparaffinized with xylene, rehydrated, and endogenous peroxidase was quenched by $3 \%$ hydrogen peroxide in methanol. Slides were then subjected to antigen retrieval by boiling in citrate buffer, $\mathrm{pH} 6$, blocked with $10 \%$ normal goat serum, and incubated with the primary antibody P16 for HPV infection. Following additional washes, color was developed using the AEC reagent (Sigma, St. Louis, MO), sections counterstained with hematoxylin, and mounted. Slides were scored by two independent oral pathologists as 0-no staining, 1-only nuclei staining, 2-nuclei and cytoplasmic staining, and 3total cell staining.

\section{DNA extraction and polymerase chain reaction}

DNA extraction: All the tissues were immersed in RNA later solution (Rehnium, Modi'in, Israel), after they were they deparaffinized in xylene, and digested overnight with proteinase $\mathrm{K}$ at $56^{\circ} \mathrm{C}$ (Rehnium, Modi'in, Israel), DNA was isolated using TRI reagent according to the manufacturer's instructions (Sigma, St. Louis, MO).

Briefly, $1 \mathrm{ml}$ of TRI reagent was added to the biopsies, the biopsies were then homogenized and incubated at room temperature for 5 minutes. Chloroform $(200 \mu \mathrm{l})$ was added to each biopsy, and then centrifuged for 15 minutes. The DNA interphase was isolated and placed in $300 \mu$ of $100 \%$ Ethanol. For DNA wash we used $0.1 \mathrm{M}$ sodium citrate solution (Sigma, Rehovot, Israel) and $1 \mathrm{ml}$ of $75 \%$ Ethanol. After two cycles of washes the pellet was dried and dissolved in $200 \mu$ l of sterile water (DDW).

The quality and quantity of the DNA was then measured using NanoDrop ND-1000 spectrophotometer (Nano-Drop Technologies, Wilmington, DE, USA), DNA samples were stored at $220^{\circ} \mathrm{C}$ until amplification for HPV testing.

Polymerase chain reaction: The isolated DNA was then subjected to a Polymerase Chain Reaction (PCR). The amplification of HPV DNA was performed in $50 \mu \mathrm{l}$ reaction tubes. Each microtube contained $2 \mu$ lextracted genomic DNA (50 ng/L), $12.5 \mu \mathrm{L}$ PCR Taq Mix (Promega Corporation, Israel), $1.5 \mu \mathrm{l}$ of each of the primers: HPV-16/F 5' TCA AAA GCC ACT GTG TCC TG 3', HPV-16/R 5' CGT GTT CTT GAT GAT CTG CA 3' with a predicted 130 bp construct, HPV-18/F5' GAC ACA TTG GAA AAA CTA AC 3', HPV-18/R 5'TAG TGC CCA GCT ATG TTG TG 3', $7.5 \mu \mathrm{L}$ of DEPC, for a total volume of $25 \mu \mathrm{L}$.

For HPV amplification and specific genotype detection, gradient reaction was first performed in order to determine the ideal annealing temperature, gradient reaction was performed for HPV genomic type primers (HPV16, HPV18) using a pool of DNA (7 neoplastic tissues).

The ideal temperature for HPV16 primers by the gradient reaction was $53^{\circ} \mathrm{C}$. For HPV18 primers there was no expression in the gel-electrophoresis analysis. PCR was performed with 35 amplification cycles. As negative control, sterile water was utilized in place of the $2 \mu \mathrm{L}$ DNA sample.

The length of the DNA segments was measured by electrophoresis on 2\% Agarose gel alongside a DNA ladder (Novagen, Roma). Gels were stained using 10\% EtBr (OmniPur. $10 \mathrm{mg} / \mathrm{ml}$, EMD Millipore,Germany). 


\section{Statistical analysis}

Chi-square and Fisher's exact test were used to investigate the relationship between HPV expression and clinical data (such as age, sex), population (Arabs, Jews, Druze), tumor related data (such as tumor primary location, histological differentiation, and pathological $\mathrm{N}$ staging), habits such as smoking and alcohol consumption. Also, survival analysis was performed using the Kaplan-Meier (KM) curves regarding HPV positive patients versus HPV negative patients. $P$ value $<0.05$ was considered statistically significant. Statistical analyses were performed using SPSS v22.

\section{Results}

The study cohort included 82 OSCC patients, spanning the period between 1996 - 2014, 53 men and 29 woman, median age 64.15 years (range, 26-94). 54 of the cohort were Jews, 25 Arabs, and only 3 patients were Druze. A significant portion of the patients reported smoking habits $(n=43)$, while, only 6 patients reported alcohol consumption.

The most common site of OSCC in the study cohort was the buccal mucosa, followed by the tongue and the floor of the mouth $(23,25$, and 17 respectively). Most of the tumors presented a will histological differentiation pattern $(n=50)$, and the vast majority of the patients were pathologically NO in the final tumor resection.

All the patients underwent " intent to treat" protocols, while the treatment of choice in all the patients was surgical resection of the primary treatment with an objective of achieving a disease-free state (oncological free margins (>7 $\mathrm{mm}$ ), neck dissection (level I-IV), and adjuvant radiotherapy as indicated. Adjuvant radiotherapy was given for positive cervical lymph nodes or negative margins of less than $4 \mathrm{~mm}$ $(n=30)$. Radiotherapy was initiated within 4 to 8 weeks after surgery with a total dose of 60-70 Gy (delivered in 2 Gy fractions).

One patient developed second primary tumor of the upper aerodigestive tract (lung), 12 patients developed local recurrences, and 1 patient developed distal metastasis (to the lung). Among the study group, 33 patients died, 28 of them from oral cancer, the overall estimated survival time was 152 months, demographic and disease related data of the study group is presented in Table 1.

Table 1 Clinical and disease related data of the study cohort (82 OSCC patients).

\begin{tabular}{|c|c|c|c|}
\hline Characteristic & Num. (\%) & Characteristic & Num. (\%) \\
\hline Total & 82 & \multicolumn{2}{|l|}{ Histological grading } \\
\hline Jews & $54(66)$ & Well differentiated & $50(61)$ \\
\hline Arabs & $25(30)$ & Moderate differentiated & $27(33)$ \\
\hline Druze & $3(4)$ & Poorly differentiated & $5(6)$ \\
\hline \multirow[t]{4}{*}{ Male / Female } & \multirow[t]{4}{*}{$53 / 29$} & P16 IHC & $32(39)$ \\
\hline & & Strong staining (3) & $7(9)$ \\
\hline & & Moderate staining (2) & $11(13)$ \\
\hline & & Mild staining (1) & $14(17)$ \\
\hline \multirow[t]{5}{*}{ Median age (std.) } & \multirow[t]{5}{*}{64.15 yrs. $(17.30)$} & \multicolumn{2}{|c|}{ Pathological N classification } \\
\hline & & No & $62(75)$ \\
\hline & & $\mathrm{N} 1$ & $10(12)$ \\
\hline & & N2 & $8(10)$ \\
\hline & & N3 & $2(3)$ \\
\hline \multicolumn{2}{|l|}{ Smoking habits } & \multicolumn{2}{|l|}{ Treatment } \\
\hline Yes & $43(48)$ & Primary resection & $82(100)$ \\
\hline No & $39(52)$ & Radiotherapy & $30(36)$ \\
\hline Alcohol consumption & $6(7)$ & Radio-chemotherapy & $2(2)$ \\
\hline \multicolumn{2}{|l|}{ Site of primary tumor } & Survivals & $50(61)$ \\
\hline Base of tongue & $11(13)$ & & \\
\hline Lateral tongue & $14(17)$ & & \\
\hline Buccal mucosa & $23(28)$ & & \\
\hline
\end{tabular}




\begin{tabular}{|l|l|}
\hline Floor of the mouth & $14(17)$ \\
\hline Gum & $1(1)$ \\
\hline Lower alveolus & $5(6)$ \\
\hline Upper alveolus & $14(17)$ \\
\hline
\end{tabular}

32 cases were P16 positive (39\%); 14, 11, and 7 had mild (1), moderate (2), and strong (3) patterns, respectively (see Materials and methods for criteria) (Figure 1). Most of those belong to tumors located in the tongue (14/32), while all of the P16 positive belonging to tumors located in the floor of the mouth were strongly stained.

The overall incidence of HPV expression (considering P16 IHC and HPV16 Taq Mix (Promega Corporation, Israel) PCR) was $45 \%(n=37)$, HPV16 DNA was detected in 23 cases $(28 \%)$, while 19 of those were also positive for P16 protein expression ( $P$ value $<0.001$ )

The median age of HPV16 positive patients was 53, versus 65.8 in the negative group ( $P$ value $<0.001$ ), also, when patients were divided into younger than 50 years and older than 50 years, $63 \%$ of the patients were HPV16 positive.

A significant relation was also found between histological differentiation, and HPV16-pos. patients; HPV16 pos. patients presented a higher histological differentiation ( $P$ value $=0.045$ ).

The $\mathrm{N}$ status was not significantly different between the two groups, still, 20 out of 23 patients in the HPV16 pos. group were pathologically NO.

No significant relation was found between HPV16 detection and smoking, alcohol habits, gender, and the different subpopulations (Table 2), though a tendency was found between HPV16 presence and Jewish patients (15/39).

The 5-year overall survival of HPV16-pos. patients was $73.9 \%$, versus $55.9 \%$ in HPV16-neg. patients, however, no statistically significant difference was found between those two variables ( $P$ value $=0.1$ ) (Figure 2 ).

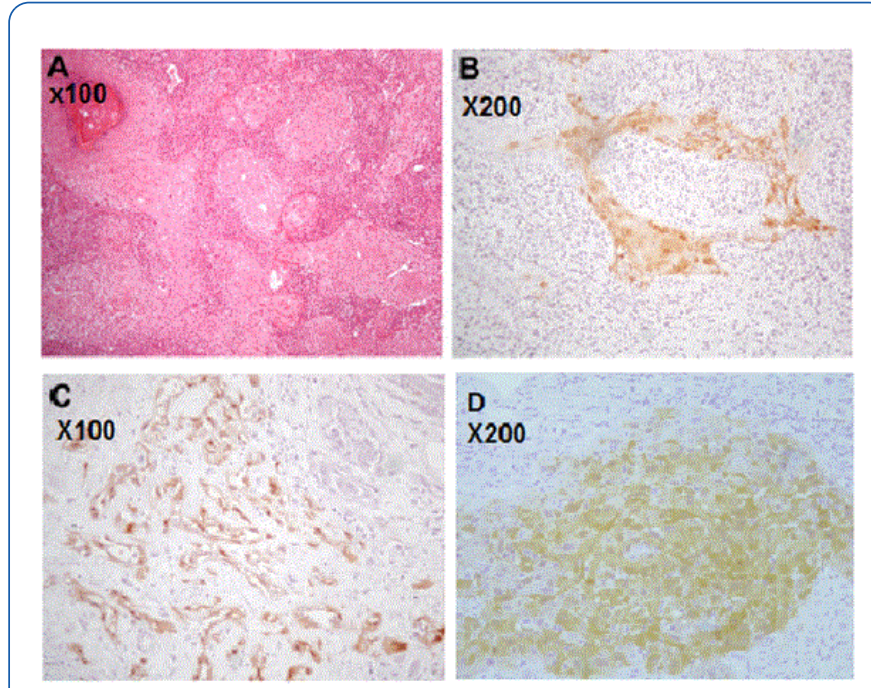

Figure 1 Example case of squamous cell carcinoma associated with proliferative verrucous leukoplakia. A) Well differentiated squamous cell carcinoma (hematoxylineosin), original magnification $\times 100)$. B) Positive moderate P16 nuclear expression (original magnification 200X). C and D) Example case of well-differentiated squamous cell carcinoma and perineural invasion (hematoxylin-eosin, original magnification $\times 100$ ). C, Positive P16 nuclear expression (original magnification 100X). D, strong positive staining for P16 nuclear and cytoplasmic (original magnification 200X).

Table 2 Clinical and histological data related to HPV DNA expression.

\begin{tabular}{|c|c|c|c|}
\hline Characteristic & HPV pos. num. & HPV neg. num. & $P$ value \\
\hline \multicolumn{3}{|l|}{ Gender } & 0.086 \\
\hline Male & 18 & 35 & \\
\hline Female & 5 & 24 & \\
\hline \multicolumn{3}{|l|}{ Smoking habits } & 0.68 \\
\hline Yes & 11 & 38 & \\
\hline No & 12 & 27 & \\
\hline \multicolumn{3}{|l|}{ Alcohol consumption } & 0.21 \\
\hline Yes & 3 & 3 & \\
\hline No & 20 & 56 & \\
\hline
\end{tabular}




\begin{tabular}{|c|c|c|c|}
\hline Median age & 53 & 65.8 & $<.001$ \\
\hline \multicolumn{3}{|l|}{ Population } & 0.56 \\
\hline Jews & 15 & 39 & \\
\hline Non-jews & 8 & 20 & \\
\hline P16 IHC staining & 21 & 10 & $<.001$ \\
\hline \multicolumn{3}{|l|}{ Histological differentiation } & 0.045 \\
\hline Well differentiation & 18 & 32 & \\
\hline Moderate differentiation & 5 & 22 & \\
\hline Poorly differentiated & 0 & 5 & \\
\hline \multicolumn{3}{|l|}{ Pathological N staging } & 0.18 \\
\hline Pos. N & 3 & 15 & \\
\hline Neg. $N$ & 20 & 44 & \\
\hline Survivals & 17 & 33 & 0.349 \\
\hline Total & 23 & 59 & \\
\hline
\end{tabular}

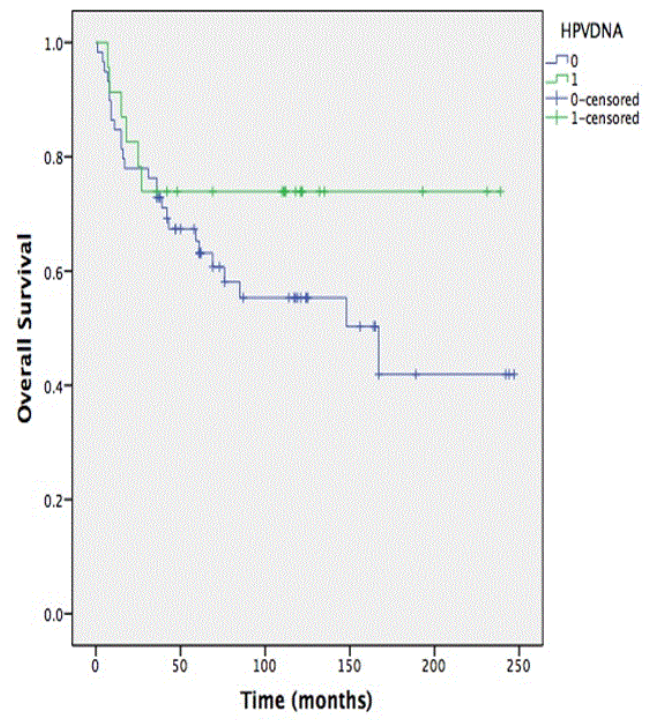

Figure 2 Kaplan-Meier curves showing overall survival probabilities in patients with HPV-positive (green) and HPVnegative (blue) neoplasms, $\mathrm{p}<0.05$.

In analyzing the tumor anatomical site, and HPV16 detection, a significant relation $(P$ value $=0.04)$ was found between tongue squamous cell carcinoma and HPV16 positivity (12/23), no difference was found regarding the tumor specific site in the tongue (base of the tongue versus lateral tongue).

\section{Discussion}

In the present study we attempted to investigate the incidence of HPV viral infection in oral squamous cell carcinoma in the Israeli population.
In 1983, Stina Syrjanen proposed evidence of Human Papilloma Virus (HPV) as an etiological factor in oral squamous cell cancer, by analyzing the presence of HPV antigens in 40 oral carcinomas using immunohistochemistry (IHC). Of the 40 lesions, 16(40\%) showed HPV-suggestive changes on light microscopy, and of those, 8 expressed HPV structural proteins [14].

Until 1997, 2380 oral carcinomas had been analyzed for HPV DNA by different techniques, and $31 \%$ were reported to contain HPV. Between 1998 and 2002, 19 additional HPV DNA samples were positive [15].

The latest meta-analyses of the epidemiological studies as well as the multi-center case-control studies have confirmed that HPV as an independent risk factor for oral cancer, with a range of odds ratios (OR) between 3.7 and 5.4 [16].

Molecular and epidemiologic data associate high-risk HPV infection with cancers that arise in the oral cavity in almost $40 \%$ of the cases; compatible with this data, the present study revealed $45 \%$ incidence of HPV (when considering either HPVDNA detection, and $\mathrm{P} 16 \mathrm{IHC}$ ) infection in OSCC.

Israel represents a developed country with relatively low percentage of alcohol consumption and high sun exposure. Data from this region demonstrated dissimilar distributions in comparison with other 'Westernized' countries. The over-all updated incidence of OSCC in Israel in 2012 was 6.48 (All rates are per 100,000; Standardization to the "Segi World standard population"); 5.14 in Jews, and 1.34 in Non-jews (0.2\%). This prevalence 5 folds less than the estimated prevalence in Europe (1\%). Israel is a heterogenic country, regarding ethnic and sub-population groups, whom differ mainly in cultural habits, socioeconomic status, and exposure to environmental carcinogens [17], this heterogeneity is also demonstrated in OSCC prevalence and trends, in the present study Jews OSCC incidence was $66 \%$, compared with $34 \%$ in Non-jews, this different may be attributed to the different genetic 
background, and environmental habits, such as alcohol consumption and smoking. Surprisingly, no significant different was found between HPV16 presences and the sub-groups, despite the difference in the sexual behavior between those two sub-population. Regarding gender distribution of OSCC, the results of the current study is compatible with world-wide epidemiological studies, indicating a significant higher male ratio (almost two fold).

It is known that DNA tumor virus infection leads to immortalization of an infected cell through down-regulation of multiple cellular pathways via expression of many potent onco-proteins [18]. Research on various viral onco-proteins has revealed many of their novel cellular targets that are directly associated with cellular signaling, cell-cycle control, and the host defense system. Tumor viruses reprogram the host quiescent, $\mathrm{GO}$ cell into the $\mathrm{S}$ phase of the cell cycle, allowing viral access to the nucleotide pools and cellular machinery that are required for replication and transmission.

The host cellular innate immune responses respond to viral infection by activating tumor suppressor proteins $\mathrm{pRb} 1$ and p53 to induce cell death. However, the tumor viruses have evolved the means to inactivate these signaling pathways for their own benefit [19-21]. Herpes-virus family members EBV and KSHV encoded onco-proteins have been shown to manipulate $\mathrm{p} 53$ and $\mathrm{pRb}$ functional activity to block apoptosis. Other DNA tumor virus-encoded onco-proteins also target tumor suppressor proteins; HPV-encoded E6 protein has been shown to bind and degrade p53 through the ubiquitinproteasome pathway [22]. In addition, HPV E7 onco-protein bypasses cell cycle arrest through binding to the hypophosphorylated form of $\mathrm{pRb}$, thereby inducing the degradation of $\mathrm{pRb}$ through a proteasome-mediated pathway [23].

The prognosis of patients suffering from OSCC varies according to the tumor specific site, pathophysiology, biological behavior, age, and radiotherapy sensitivity [24]. HPV have been proposed to play a prognostic role in OSCC in several studies, the molecular processes responsible for the better prognosis observed in patients with HPV-positive cancers are not yet clear. An association between HPV positivity and radiosensitivity of oropharyngeal tumors has been demonstrated [25], suggesting that the effect of HPV may be treatment dependent. This theory is consistent with the survival advantage observed for those with Stage IV disease who are primarily treated with radiotherapy and chemotherapy. This theory is also supported by in vitro studies indicating that interaction between the HPV E6 and the p53 proteins does not inactivate p53 completely [26]. If this is true, the presence of E6 may not correspond functionally to mutations in the p53 gene. Along the same lines, it has been hypothesized that radiation and other toxic agents may decrease the capacity of HPV E6/E7 to interfere with p53/pRb and other host proteins, rendering the cancers more susceptible to therapy. In the present study, no significant relation was found between the over-all survival rate and HPV detection, however, a significant relation was found between the histological differentiation and HPV detection, which could absolutely indicate a better prognosis.

A large retrospective cytological analysis, conducted a decade ago, including 3444 liquid based cytology samples, showed that Younger women were significantly more likely to harbour multiple high risk HPV infections [27], which indicate a younger target population, in the present study a significant age difference was found between HPV pos. patients, and HPV neg. patients (53 vs. 65.8). Also, a significant relation was found between HPV-DNA detection, and P16 presence ( $P$ value $<0.001)$ which could indicate the strong relation between those two parameters.

In conclusion, based on the current study results, a different and unique nature of HPV related OSCC is suggested, a younger population, a significant higher P16 protein expression, and better histological differentiation. Moreover, the prevalence of HPV related OSCC in Israel lower (28\%, HPVDNA) compared to other countries in the Western world, with HPV-16 the dominant type. Also, no significant clinical different was found between HPV pos. patients and HPV neg. patients (alcohol, smoking and sub-population).

The retrospective nature of the current study, along with the small number of patients, are major limitation in drawing firm conclusion, still, this data may be the start of many to come regarding HPV related OSCC nature in Israel.

\section{References}

1. Beaglehole R, Irwin A, Prentice T (2003) The World Health Report 2003: Shaping the Future.

2. Brunicardi F, Andersen D, Billiar T, Dunn D, Hunter J, et al. (2009) Schwartz's Principles of Surgery, (9th Edn), McGraw-Hill Education, USA.

3. Doherty G (2009) Current Diagnosis and Treatment Surgery. (13th edn), McGraw-Hill, USA.

4. Massano J, Regateiro FS, Januário G, Ferreira A (2006) Oral squamous cell carcinoma: review of prognostic and predictive factors. Oral Surg Oral Med Oral Pathol Oral Radiol Endod 102: 67-76.

5. Li W, Thompson C, O'Brien C, McNeil E, Scolyer R, et al. (2003) Human papillomavirus positivity predicts favourable outcome for squamous carcinoma of the tonsil. Int J Cancer 106: 553-558.

6. Rosenquist K, Wennerberg J, Annertz K, Schildt EB, Hansson BG, et al. (2007) Recurrence in patients with oral and oropharyngeal squamous cell carcinoma: human papillomavirus and other risk factors. Acta Otolaryngol 127: 980-987.

7. Engels EA, Biggar RJ, Hall HI, Cross H, Crutchfield A, et al. (2008) Cancer risk in people infected with human immunodeficiency virus in the United States. Int J Cancer 123: 187-194.

8. Duray A, Descamps G, Arafa M, Decaestecker C, Remmelink M, et al. (2011) High incidence of high-risk HPV in benign and malignant lesions of the larynx. Int J Oncol 39: 51-59.

9. Annertz K, Anderson H, Biörklund A, Möller T, Kantola S, et al. (2002) Incidence and survival of squamous cell carcinoma of the tongue in Scandinavia, with special reference to young adults. Int J Cancer 101: 95-99. 
10. Weinberger $P, Y u Z$, Haffty B, Kowalski D, Harigopal M, et al. (2006) Molecular classification identifies a subset of human papillomavirus-associated oropharyngeal cancers with favorable prognosis. J Clin Oncol 24: 736-747.

11. Dahlstrand $H$, Nasman $A$, Romanitan $M$, Lindquist $D$, Ramqvist $T$, et al. (2008) Human papillomavirus accounts both for increased incidence and better prognosis in tonsillar cancer. Anticancer Res 28: 1133-1138.

12. Fischer C, Zlobec I, Green E, Probst S, Storck C, et al. (2010) Is the improved prognosis of p16 positive oropharyngeal squamous cell carcinoma dependent of the treatment modality? Int J Cancer 126: 1256-1262.

13. Ragin CC, Taioli E (2007) Survival of squamous cell carcinoma of the head and neck in relation to human papillomavirus infection: review and meta-analysis. Int J Cancer 121: 1813-1820.

14. Syrjanen KJ, Pyrhonen S, Syrjanen SM, Lamberg MA (1983) Immunohistochemical demonstration of human papilloma virus (HPV) antigens in oral squamous cell lesions. Br J Oral Surg 21: 147-153.

15. Metgud R, Astekar M, Verma M, Sharma A (2012) Role of viruses in oral squamous cell carcinoma. Oncol Rev 6: e21.

16. Syrjänen S (2005) Human papillomavirus (HPV) in head and neck cancer. J Clin Virol 32 Suppl 1: S59-66.

17. Amit M, Ilana K, Avraham SP, Binenbaum Y, Bachar G, et al. (2016) Trends in human papillomavirus-related oropharyngeal cancer in Israel. Head Neck 38 Suppl 1: E274-278.

18. Saha A, Kaul R, Murakami M, Robertson E (2010) Tumor viruses and cancer biology: Modulating signaling pathways for therapeutic intervention. Cancer Biol Ther 10: 961-978.
19. Frisch M, Biggar RJ, Engels EA, Goedert JJ (2001) Association of cancer with AIDS-related immunosuppression in adults. JAMA 285: 1736-1745.

20. Oliner J, Min H, Leal J, Yu D, Rao S, et al. (2004) Suppression of angiogenesis and tumor growth by selective inhibition of angiopoietin-2. Cancer Cell 6: 507-516.

21. Rathinam R, Alahari SK (2010) Important role of integrins in the cancer biology. Cancer Metastasis Rev 29: 223-237.

22. Moore P, Chang Y (2010) Why do viruses cause cancer? Highlights of the first century of human tumour virology. Nat Rev Cancer 10: 878-889.

23. Damania B (2007) DNA tumor viruses and human cancer. Trends Microbiol 15: 38-44

24. Bosch FX, Lorincz A, Munoz N, Meijer CJ, Shah KV (2002) The causal relation between human papillomavirus and cervical cancer. J Clin Pathol 55: 244-265.

25. Lindel K, Beer KT, Laissue J, Greiner RH, Aebersold DM (2001) Human papillomavirus positive squamous cell carcinoma of the oropharynx: a radiosensitive subgroup of head and neck carcinoma. Cancer 92: 805-813.

26. Kiyono T, Hiraiwa A, Fujita M, Hayashi Y, Akiyama T, et al. (1997) Binding of high-risk human papillomavirus E6 oncoproteins to the human homologue of the Drosophila discs large tumor suppressor protein. Proc Natl Acad Sci 94: 11612-11616.

27. Cuschieri KS, Cubie HA, Whitley MW, Seagar AL, Arends MJ, et al. (2004) Multiple high risk HPV infections are common in cervical neoplasia and young women in a cervical screening population. Journal of clinical pathology 57: 68-72. 